\title{
17. A MAGNETO-PETROLOGICAL STUDY OF ROCKS FROM LEG 83, HOLE 504B, DEEP SEA DRILLING PROJECT1
}

\author{
D. Facey, J. Housden, and W. O'Reilly, Department of Geophysics and Planetary Physics, \\ University of Newcastle upon Tyne ${ }^{2}$
}

\begin{abstract}
Twenty-seven samples from the Leg 83 section of Hole 504B have been investigated using magnetic, optical, and electron optical methods. The primary magnetic mineral to crystallize was titanomagnetite of approximate composition $\mathrm{Fe}_{2.4} \mathrm{Ti}_{0.6} \mathrm{O}_{4}$ (TM60), but none survives, nor is there evidence of titanomaghemite produced by oxidation of TM60. The average measured magnetic properties can be interpreted in terms of magnetite, $\mathrm{Fe}_{3} \mathrm{O}_{4}$, having average grain size of $\leq 1$ $\mu \mathrm{m}$ and present in average volume concentration of $\sim 0.5 \%$. The intensity of the natural remanent magnetization (NRM) of the rocks could also be accounted for as being a thermoremanence carried by this mineral.

Although the heterogeneity of the titanomagnetite grains could be detected optically, the texture of the intergrown phases is poorly developed. In some samples from the massive units of the lower part of the section, trellis patterns were visible. The $\mathrm{Fe}_{3} \mathrm{O}_{4}$ present in the intergrowths is too intimately mixed with the other intergrown phases to be revealed by electron microprobe analysis that simply returns the bulk composition of the intergrowth (oxidized TM60). The path by which the mineral assemblage evolved from TM60 to an $\mathrm{Fe}_{3} \mathrm{O}_{4}$-containing intergrowth, under the temperature and pressure conditions obtaining in the Leg 83 section, makes interesting speculation. Deuteric oxidation, maghemitization/inversion, or some hypothetical low-temperature/high-pressure oxidation by a leaching-of-iron process may all play roles.
\end{abstract}

\section{INTRODUCTION}

In this chapter we present the results of a study of the magnetic properties of 27 samples from Leg 83, Hole 504B. The magnetic properties are of interest both as an indicator of the performance of these basement rocks as contributors to anomalies in the geomagnetic field and also as a means of determining the composition, concentration, and microstructure of the magnetic minerals and their petrological history (Fig. 1). A knowledge of the path taken by the magnetic mineral assemblage over geological time can contribute to solutions of the geophysical and geochemical problems of that part of the submarine crust.

The primary magnetic mineral of newly constructed submarine crust formed at spreading centers is titanomagnetite, in simple form $\mathrm{Fe}_{3-x} \mathrm{Ti}_{x} \mathrm{O}_{4}$, but inevitably nonstoichiometric and containing species of cation other than $\mathrm{Fe}$ and $\mathrm{Ti}$. The general titanomagnetite $\mathrm{Fe}_{(3-x-a) R^{-}}$ $\mathrm{Ti}_{x R} \mathrm{M}_{a R} \square_{3(1-R)} 0_{4}$ may be regarded as being obtained by substitution of $\mathrm{Fe}$ ions by divalent and/or trivalent ions, $M$, and the resultant complex titanomagnetite oxidized. This reduces the cation/anion ratio from the $3 / 4$ of stoichiometry to a ratio $3 R / 4$. As $R$ falls below unity, the number of cations per formula unit decreases and the number of vacancies $\square$ increases. An oxidation parameter, $z$, may also be introduced, where $z$ is the fraction of the $\mathrm{Fe}^{2+}$ in the complex stoichiometric titanomagnetite oxidized to $\mathrm{Fe}^{3+} . R$ is related to $z: R=8 /(8+z[1$ $+x-b]$ ), where $b$ is the number of divalent ions per formula unit of other species than $\mathrm{Fe}^{2+}$ in the unoxi-

\footnotetext{
${ }^{1}$ Anderson, R. N., Honnorez, J., Becker, K., et al., Init. Repts. DSDP, 83: Washington (U.S. Govt. Printing Office).

2 Address: Department of Geophysics and Planetary Physics, School of Physics, University of Newcastle upon Tyne, Newcastle upon Tyne, NEI 7RU, United Kingdom.
}

dized complex titanomagnetite. The composition of parameters $x$ and $z$ determined using the electron probe microanalyzer (EPMA) (Table 1) are based on the previous formula for a complex nonstoichiometric titanomagnetite.

The composition of the titanomagnetite crystallizing in the upper basaltic regions of crust may be approximated to $x=0.6$ (TM60 in Fig. 1). A composition nearer to $x=0$ may be appropriate in deeper-seated gabbroic submarine crust (Dunlop and Prévot, 1982), nearer $\mathrm{Fe}_{3} \mathrm{O}_{4}$ in Figure 1. The course of the subsequent history of the magnetic mineral during its journey from spreading center to subduction zone, during which it may experience several modes of alteration, is shown schematically in Figure 1. The general trend is to the right (oxidation, increasing $z$ ) and downward (decreasing $x$ ), hematite $\left(\alpha \mathrm{Fe}_{2} \mathrm{O}_{3}\right)$ being the last significantly magnetic phase before an essentially nonmagnetic iron-bearing mineral is formed by some weathering process. The fine-grain titanomagnetite of quenched basalts, presumably because of its large specific surface and the conditions peculiar to submarine weathering, seems especially likely to undergo maghemitization to produce metastable titanomaghemites. Such material undergoes inversion to a more stable assemblage of phase on raising the temperature (generally at about $350^{\circ} \mathrm{C}$ at atmospheric pressure) or raising the pressure [at $1.5 \mathrm{MPa}$ at $0^{\circ} \mathrm{C}$ (Kushiro, 1960)]. This inversion in the laboratory, observed in the course of heating during thermomagnetic runs, is a qualitative and potentially quantitative means by which the degree of maghemitization can be determined (O'Reilly, 1983). The dominant magnetic constituent of the inverted product is magnetite.

In a more slowly cooling basaltic unit, the initially crystallizing titanomagnetite may undergo deuteric oxidation at elevated temperatures due to the oxidizing 


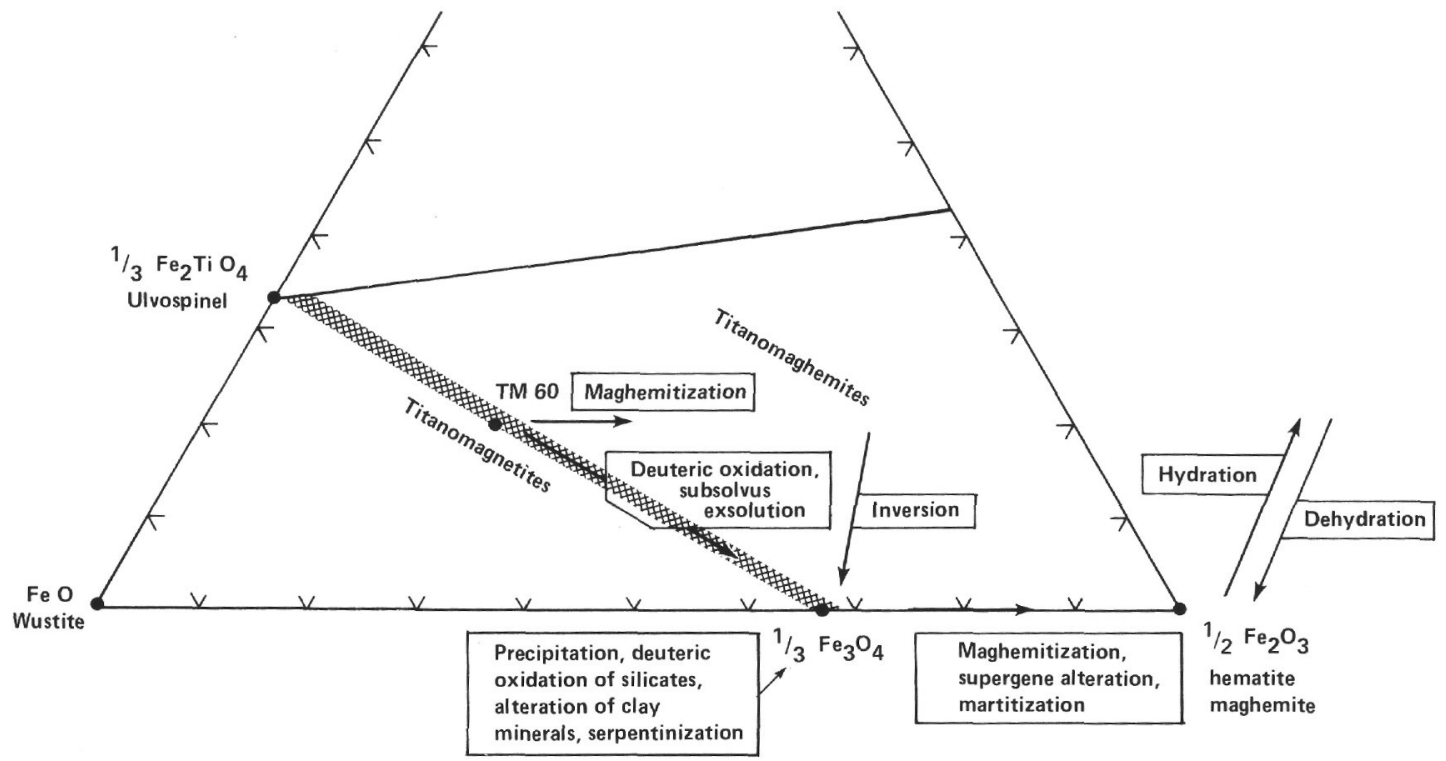

Figure 1. Summary of the processes a freshly crystallized titanomagnetite may undergo during its geological history. The maghemitization process may be widespread and take place rapidly in the lavas of the submarine crust. Deeperseated intrusive rocks may undergo deuteric alteration during slow cooling.

Table 1. Sample numbers, depth below seafloor, and measured magnetic properties.

\begin{tabular}{|c|c|c|c|c|c|c|c|c|c|c|c|}
\hline $\begin{array}{c}\text { Sample } \\
\text { No. }\end{array}$ & $\begin{array}{c}\text { Sample } \\
\text { (interval in } \mathrm{cm} \text { ) }\end{array}$ & $\begin{array}{l}\text { Depth } \\
\text { (m) }\end{array}$ & Unit & $\begin{array}{l}\mathrm{NRM} \\
(\mathrm{A} / \mathrm{m})\end{array}$ & $\begin{array}{c}\text { Inc. } \\
\left({ }^{\circ}\right)\end{array}$ & $\begin{array}{c}\chi \\
\left(10^{-3}\right)\end{array}$ & $\begin{array}{c}H_{c} \\
\left(10^{3} \mathrm{~A} / \mathrm{m}\right)\end{array}$ & $\underset{\left(10^{3} \mathrm{~A} / \mathrm{m}\right)}{M_{S}}$ & $M_{r s} / M_{S}$ & $M_{F^{\prime}} M_{I}$ & $Q_{n}$ \\
\hline 1 & $71-1,130-132$ & 837.31 & 47 & 3.21 & - & 27.0 & 6.30 & 2.60 & 0.131 & 0.99 & 3.8 \\
\hline 2 & $72-2, \quad 61-63$ & 845.62 & 47 & 2.24 & -29 & 41.1 & 4.93 & 2.79 & 0.108 & 0.60 & 1.8 \\
\hline 3 & $73-1, \quad 15-17$ & 852.66 & 50 & 1.69 & -25 & 22.7 & 9.31 & 2.84 & 0.160 & 0.64 & 2.4 \\
\hline 4 & $73-2, \quad 13-15$ & 854.14 & 50 & 2.12 & -25 & 22.2 & 14.6 & 2.83 & 0.248 & 0.60 & 3.1 \\
\hline 5 & $74-1,125-127$ & 862.76 & 51 & 0.21 & -28 & 38.0 & 6.4 & 3.99 & 0.098 & 0.75 & 0.2 \\
\hline 6 & $75-2, \quad 37-39$ & 872.38 & 52 & 1.15 & - & 22.2 & 6.7 & 3.61 & 0.109 & 0.93 & 1.7 \\
\hline 7 & $76-1, \quad 56-58$ & 880.07 & 53 & 1.13 & -10 & 18.5 & 16.1 & 3.39 & 0.224 & 0.88 & 2.0 \\
\hline 8 & $77-1, \quad 74-76$ & 889.25 & 54 & 0.49 & - & 43.2 & $\begin{array}{r}10.1 \\
5.7\end{array}$ & 4.20 & 0.091 & 0.82 & 0.4 \\
\hline 9 & $78-2, \quad 71-73$ & 899.72 & 57 & 1.14 & -32 & 25.9 & 15.7 & 3.66 & 0.220 & 0.70 & 1.4 \\
\hline 10 & $79-2, \quad 80-82$ & 906.81 & 59 & 1.65 & -21 & 21.2 & 10.9 & 2.42 & 0.182 & 0.83 & 2.5 \\
\hline 11 & $80-1,126-128$ & 911.27 & 60 & 0.01 & -8 & 0.3 & 4.4 & 0.01 & 0.290 & 4.30 & 1.1 \\
\hline 12 & $80-3, \quad 85-87$ & 913.86 & 60 & 0.02 & -9 & 0.6 & 7.7 & 0.02 & 0.320 & 1.80 & 1.2 \\
\hline 13 & $82-1, \quad 51-53$ & 929.02 & 60 & 0.24 & -65 & 4.5 & 15.3 & 0.52 & 0.244 & 1.10 & 1.8 \\
\hline 14 & $83-1, \quad 74-76$ & 938.25 & 60 & 0.01 & +13 & 0.6 & 5.3 & 0.01 & 0.310 & 6.00 & 0.7 \\
\hline 15 & $84-1, \quad 81-83$ & 947.32 & 60 & 0.04 & -44 & 0.9 & 11.2 & 0.04 & 0.320 & 2.50 & 1.4 \\
\hline 16 & $85-1,117-119$ & 956.68 & 60 & 0.01 & -35 & 1.2 & 7.3 & 0.06 & 0.193 & - & 0.4 \\
\hline 17 & $85-3,103-105$ & 959.54 & 61 & 2.15 & - & 28.4 & 19.9 & 4.06 & 0.298 & 0.99 & 2.4 \\
\hline 18 & $113-1, \quad 58-60$ & 1171.59 & 115 & 1.43 & - & 16.8 & 15.0 & 2.15 & 0.231 & 1.01 & 2.7 \\
\hline 19 & $117-1, \quad 77-79$ & 1190.28 & 118 & 1.94 & -68 & 15.3 & 19.8 & 2.42 & 0.290 & 0.98 & 4.1 \\
\hline 20 & $118-1, \quad 38-40$ & 1194.39 & 118 & 1.45 & -33 & 15.5 & 20.8 & 2.40 & 0.300 & 0.97 & 3.0 \\
\hline 21 & $127-1, \quad 98-100$ & 1254.49 & 131 & 1.17 & +29 & 12.9 & 17.0 & 1.76 & 0.256 & 0.91 & 2.9 \\
\hline 22 & $129-1, \quad 66-68$ & 1270.67 & 133 & 0.61 & +27 & 10.3 & 18.3 & 1.42 & 0.286 & 0.79 & 1.9 \\
\hline 23 & $130-1,109-111$ & 1280.10 & 135 & 0.75 & +47 & 12.6 & 21.9 & 1.64 & 0.327 & 0.78 & 1.9 \\
\hline 24 & $131-1, \quad 39-41$ & 1287.90 & 136 & 0.64 & -1 & 10.8 & 21.8 & 1.55 & 0.325 & 0.91 & 1.9 \\
\hline 25 & $132-1, \quad 73-75$ & 1295.74 & 137 & 1.00 & +5 & 14.1 & 17.1 & 2.12 & 0.280 & 0.92 & 2.3 \\
\hline 26 & $133-1,106-108$ & 1305.07 & 138 & 3.52 & +10 & 19.5 & 13.1 & 2.89 & 0.213 & 0.81 & 5.8 \\
\hline 27 & $137-1,109-111$ & 1328.10 & 143 & 1.13 & +37 & 7.2 & 17.0 & 0.86 & 0.277 & 0.78 & 5.1 \\
\hline
\end{tabular}

Note: Dash indicates quantities that were indeterminate or indeterminable.

conditions within the basalt itself (Ade-Hall et al., 1971). The magnetic phase in the resultant assemblage is a progressively iron-enriched titanomagnetite. An account of the laboratory simulation of this process and its magnetic consequences is given by Tucker and O'Reilly (1980). Other processes, some of which may have importance in the context of the submarine crust are also indicated in Figure 1.
The samples of the present investigation are listed in Table 1. They may conveniently be divided into two groups, Samples 1-17 coming from the upper $120 \mathrm{~m}$ of the Leg 83 section of Hole 504B. Most of these samples are described in the lithostratigraphic chart of the section as being from brecciated or fractured pillow lavas. Samples 3, 4, 6, 8, 10, and 17 are described as massive units. A gap of $200 \mathrm{~m}$ separates Samples 17 and 18, the 
uppermost sample of the second group, which are described as coming from massive units. Samples 20 and 21 are separated by a gap of $60 \mathrm{~m}$. The lowest sample of this suite (Sample 27) has been recovered from $1330 \mathrm{~m}$ below the seafloor.

\section{MAGNETIC MEASUREMENTS}

The magnetic measurements were made using instruments standard to a rock and paleomagnetism laboratory. Remanent magnetization measurements were made with a Digico ${ }^{\circledR}$ spinner magnetometer; saturation magnetization and magnetic hysteresis parameters were provided with a vibrating sample magnetometer of the Foner type; a transformer-bridge-type susceptibility meter provided susceptibility data; a furnace-equipped vertical magnetic balance was used to study thermomagnetic behavior of samples sealed in evacuated capsules.

The intensity and inclination of the natural remanent magnetiziation (NRM) of the suite are listed in Table 1, and the intensities are plotted in Figure 2. With the exception of Samples 11,12,14, 15, and 16, which are found to differ from the rest in a number of magnetic properties, the intensities lie in the range of $0.5-3 \mathrm{~A} / \mathrm{m}$ with a mean (excluding the exceptional samples) of 1.4 $\mathrm{A} / \mathrm{m}$. This is a factor of 100 smaller than the fresh basalts of axial zones, but otherwise typical of the intensity of material from the oceanic crust. The inclinations of NRM are consistent with the latitude of Hole 504B and do not change significantly during alternating field demagnetization.

The saturation magnetization, $M_{s}$, and susceptibility, $\chi$ (Fig. 2, Table 1) follow the same pattern as the NRM, especially in the lower part of the hole. In the upper part $M_{s}$ and $\chi$ shows a similar trend throughout, but the NRM for Samples 1-9 does not mirror $M_{s}$ and $\chi$. Samples 11,12,14, 15 and 16 again stand out as exceptional in this suite in having low values of magnetic parameters.

The magnetization process parameters-coercive force, $H_{c}$, and ratio of saturation remanence to saturation magnetization $M_{r s} / M_{s}$ are shown in Figure 2 (and Table 1 ). The values are typical of those found for synthetic titanomagnetites (Robins, 1972; Day et al., 1977). Figure 2 also shows the Königsberger ratio $Q_{n}=\mathrm{NRM} / \chi H$, where $H$ is taken to be $31 \mathrm{~A} / \mathrm{m}$.

The various measured parameters depend on the concentration, composition, and microstructure of the magnetic minerals. $M_{s}$ depends on composition and concentration. $\chi$ depends on all three, whereas $H_{c}$ and $M_{r s} / M_{s}$ depend on composition and microstructure as does $Q_{n}$. The thermomagnetic properties (i.e., relative variations of high field magnetization with temperature) are composition dependent and have been used with some success in tracing variations of composition $(x, z)$ in submarine basalts (e.g., Ryall and Ade-Hall, 1975). The exploitation as an analytical technique of the inversion observed during thermomagnetic runs of maghemitized titanomagnetite has been explored experimentally for continental rocks (Inoue, 1982) and in terms of model mechanisms (O'Reilly, 1983).

No convincing evidence for inversion of titanomaghemites was found in the thermomagnetic runs of the present suite of samples. This is to be contrasted with the thermomagnetic characteristics of the Leg 69 section (down to $489 \mathrm{~m}$ below seafloor) in which irreversible thermomagnetic curves showed that maghemitization had taken place (O'Donovan and O'Reilly, 1983). All thermomagnetic runs of the present samples (with the exception of Samples 11,12,14, 15, and 16) were approximately reversible, with a single Curie point temperature between 565 and $580^{\circ} \mathrm{C}$. This would seem to indicate magnetite $(x=0)$ as the magnetic constituent, although it must be remembered that a measured Curie temperature does not uniquely define the composition of a titanomagnetite/titanomaghemite, but only confines the composition to a contour on the ternary diagram of Figure 1. Magnetite should be stable on heating in an evacuated capsule, and the magnetization before the heating run $\left(M_{I}\right)$ should be the same as that after the run $\left(M_{F}\right)$. A good indicator of maghemitization having taken place in nature is $M_{F} / M_{I}$ ratios in excess of unity.

Model calculated $M_{F} / M_{I}$ ratios rise from unity (for near-stoichiometric titanomagnetite, $x=0.6$ ) to about 5 (for $z \sim 0.5$ ) followed by a fall to a very small value at $z=1$ (O'Reilly, 1982). Some experiments on synthetic analogs support such a model, others simply suggest a steady rise in $M_{F} / M_{I}$ to about 2 near $z=1$. The reasons for the agreement or otherwise between model and data have been discussed by O'Reilly (1983). Values of $M_{F}$ / $M_{I}$ near unity therefore may be ambiguous, but departures from this value seem good evidence of $z \neq 0 . M_{F} /$ $M_{I}$ ratios for the present suite of specimens are shown in Figure 2 and Table 1. The possibility that Samples 2, 3, and $4\left(M_{F} / M_{I} \sim 0.60, T_{c} \sim 560^{\circ} \mathrm{C}\right)$ contain highly maghemitized titanomaghemite cannot be excluded although, if this were so, inversion should have been observed at $\sim 350^{\circ} \mathrm{C}$ on the heating run. The near coincidence of the heating and cooling curves and the Curie temperatures near $570^{\circ} \mathrm{C}$ suggests that the dominant magnetic mineral in the rest of the suite (except the exceptional samples) is near-stoichiometric magnetite. A representative thermomagnetic curve (that of Sample 18 ) is shown in Figure 3. Samples 11, 12, 14, 15, and 16 are almost nonmagnetic, show little variation of high field moment with temperature, and reveal no discernible Curie point on the heating run. The thermomagnetic curve of Sample 15 is also shown in Figure 3. The concentration of magnetic oxides or sulfides in these samples is so low that it is impossible to identify them by magnetic means and presumably very difficult by any means. If the magnetic phase is magnetite (with saturation magnetization $4.6 \times 10^{5} \mathrm{~A} / \mathrm{m}$ at room temperature), the average concentration in the weakly magnetic samples would be $0.007 \%$. If the mineral were hematite, the average concentration would be $1.4 \%$.

For the rest of the suite we take the presence of magnetite as a working hypothesis, the average concentration being about $0.5 \%$.

The microstructure-dependent parameters, $H_{c}$ and $M_{r s} / M_{s}$, if all samples have the same magnetic constituent, indicate a fluctuating grain size (if the possibility of other extrinsic influences such as particle-particle interactions and strain are ignored) with, possibly, a smaller 

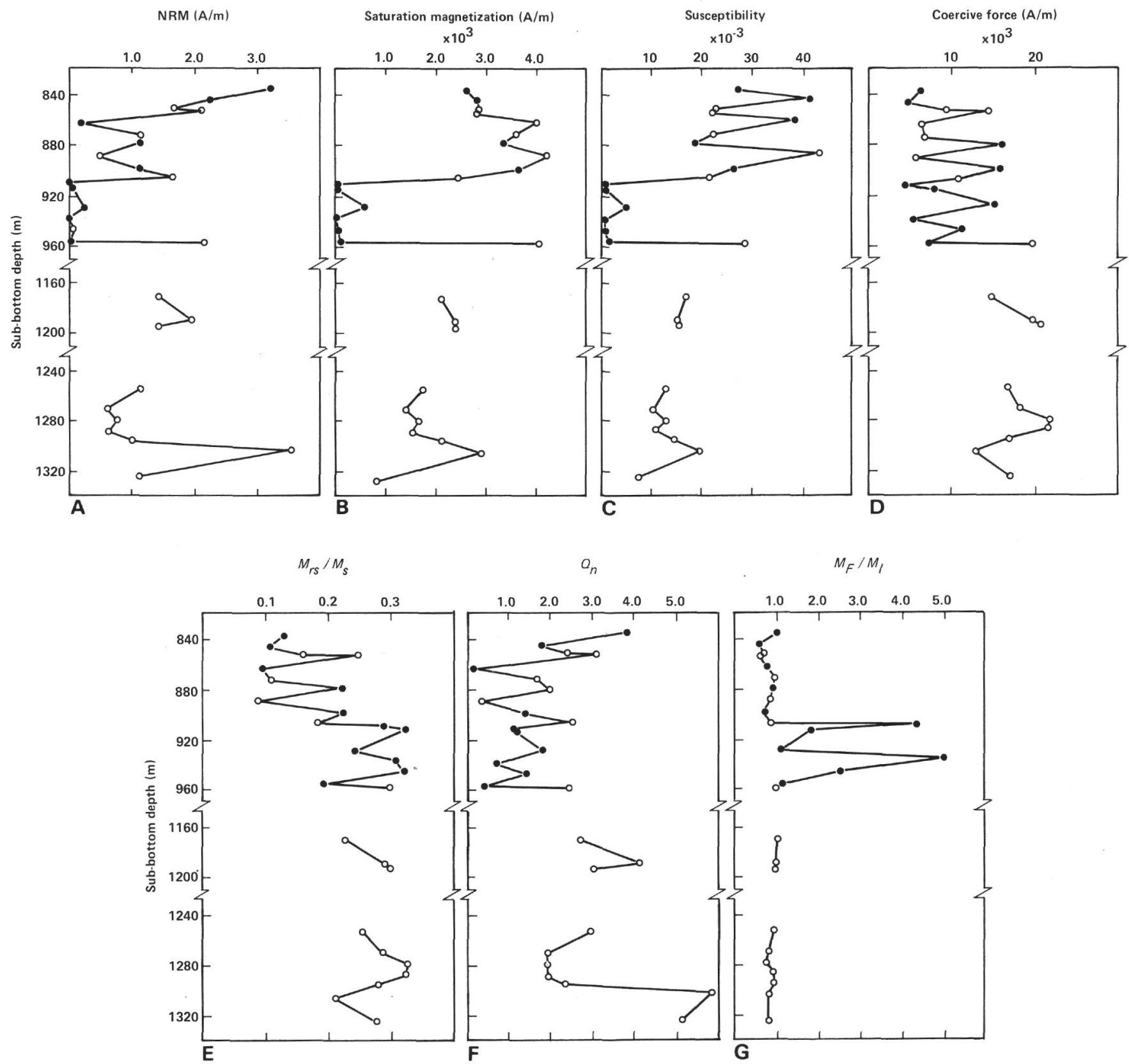

Figure 2. Variation in magnetic properties with depth. Solid symbols represent pillows, open circles massive units. A. Natural remanent magnetization; intensities are typical of submarine basement. B. Saturation magnetization indicates average magnetite/titanomagnetite/titanomaghemite concentration of $<0.5 \%$. C. Magnetic susceptibility. D. Coercive force. E. Ratio of saturation remenance to saturation magnetization $\left(M_{r s} / M_{s}\right)$. The magnetic mineral probably contains only few domains. F. Königsberger ratio $Q_{n}=\mathrm{NRM} / \chi H$. G. Ratio $\left(M_{F} / M_{I}\right)$ of the saturation magnetization after execution of a thermomagnetic run to the saturation magnetization before the run. Values of $M_{F} / M_{I}$ near unity indicate a mineral structurally stable to heating to $\sim 700^{\circ} \mathrm{C}$.

grain size in the deeper samples. The range of sizes indicated by both parameters is $\sim 1 \mu \mathrm{m}$ and smaller (Day et al., 1977). One $\mu \mathrm{m}$ magnetite has a susceptibility of typically $1.5-2$, a laboratory thermoremanent magnetization (TRM) per unit field of 10-12 (see, e.g., Dunlop, 1981) and a $Q_{T}(=\mathrm{TRM} / \chi H)$ therefore, of $\sim 5$. Taking the average NRM of Hole 504B as the TRM of $1 \mu \mathrm{m}$ magnetite at $0.5 \%$ concentration yields an ancient field of $\sim 30 \mathrm{~A} / \mathrm{m}$. The observed susceptibility is a factor of about 2 too high for a concentration of $0.5 \%$ and the observed $Q_{n}$ correspondingly lower than the expected $Q_{T}$, but on the whole the averaged properties seem well explained by the presence of magnetite of the above grain size and concentration.

The suite, of course, contains a range of grain sizes, and the variation of the properties with grain size can be illustrated by the variation of one grain-size-dependent parameter with another. As can be seen by inspection of Table 1 and Figures 2-8, pairs of $M_{r s} / M_{s}, H_{c}$, and the median destructive field of NRM show rough linear correlations. $H_{c}$ or $M_{r s} / M_{s}$ show rough inverse correlations with $\chi$. 


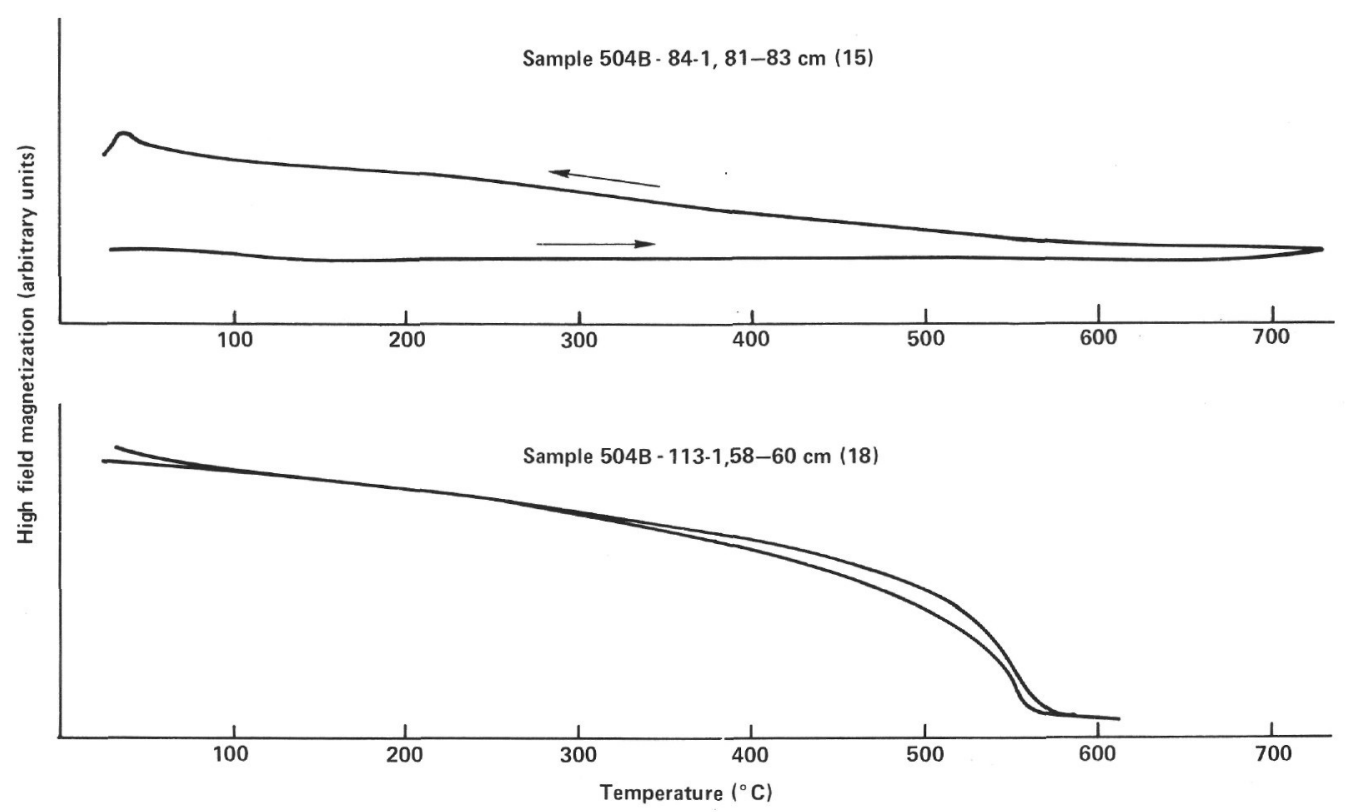

Figure 3. Representative thermomagnetic curves. Sample 15 is one of the group of very weakly magnetic specimens for which no conclusions could be reached about the contained magnetic fraction. Sample 18 is representative of the bulk of the suite, and the observed Curie point $\left(575^{\circ} \mathrm{C}\right)$ and repeatability of the curve suggests that the magnetic mineral is magnetite. The magnetization scale in the two parts of the figure is not the same. There is a factor of about 50 between the specific magnetizations of the two specimens.

No hint of the identity of the magnetic constituents of Samples $11,12,14,15$, and 16 is given by the properties of Table 1 except that, whatever their composition, they are above or near the monodomain/multidomain boundary region size range for that composition.

\section{OPAQUE MINERALOGY}

Polished mounts were prepared, care being taken to avoid excessive heating and consequent dangers of phase changes during preparation (Johnson and Merrill, 1973), and examined in reflected light at magnifications up to $\times 1050$. Table 2 summarizes the observations. The opaque minerals are minor phases consisting of titanomagnetites, sulfides, and very few hydroxides. The volume $\%$ concentrations were estimated using less than maximum magnification to ensure a representative area was scanned, and the often abundant titanomagnetite of $<1 \mu \mathrm{m}$ grain size are therefore not included. Estimates of plagioclase lath and average silicate matrix size are also given.

Optical and microprobe investigations suggest that all the sulfides are nonmagnetic pyrite, and the hydroxides are nonmagnetic limonite. The titanomagnetites are by far the most abundant of the opaques, except in Samples 11-16. The asterisks in Table 2 refer to observations on relict titanomagnetite grains in these samples. In the rest of the suite the titanomagnetites occur within the groundmass and have grain sizes roughly proportional to those of the silicate matrix. Grain sizes are smaller, and the titanomagnetite grains tend to be skeletal to subskeletal in the upper part of the section, which is believed to consist of mixed pillows and massive units (pillows, flows, and dikes). Grain sizes are larger in the lower section consisting only of massive units (dikes) and the titanomagnetites tend to be euhedral/subhedral. The titanomagnetites appear to have been one of the last minerals to crystallize, and the form and size of the grains are diagnostic of cooling rates in the later stages of cooling.

The progressive low-temperature maghemitization in submarine basalts, as observed under the microscope, has been described, well illustrated, and subdivided into five stages (Johnson and Hall, 1978). A slight whitening is followed by the formation of shrinkage cracks and veins infilled by nonopaque material. Average stages of low-temperature alteration are given in Table 2 with plus or minus added to illustrate small but possibly relevant differences between samples. The upper section generally has lower low-temperature alteration degree than the lower section, with the exception of Samples 11-16, which show the highest alteration of the whole suite. No evidence of titanomagnetite was found in Samples 11 and 12 . Sample 13 contains a few relict grains, occasionally including small granules of residual titanomagnetite (stage 5). Samples 14-16 contain only totally pseudomorphed relicts of titanomagnetite (stage $5+$ ). The high abundance of opaques in these samples is due to the presence of secondary pyrite. Smaller altered titanomagnetite grains tend to be more uniformly altered, whereas larger grains may have a relatively unaltered core, and samples toward the upper margins of units tend to be more altered than those lower in the unit.

On examination of the titanomagnetite grains under crossed polars, all samples (excluding Samples 11-16) exhibited optical anisotropy to some degree. Titanomagnetite and titanomaghemite are optically isotropic, so the grains cannot be homogenous but must contain an anisotropic phase, presumably hemoilmenite. The mi- 
Table 2. Summary of optical and electron microprobe investigation.

\begin{tabular}{|c|c|c|c|c|c|c|c|c|c|c|c|}
\hline \multirow[b]{2}{*}{$\begin{array}{l}\text { Sample } \\
\text { No. }\end{array}$} & \multicolumn{2}{|c|}{ Matrix size } & \multicolumn{2}{|c|}{ Tm. grain size } & \multirow{2}{*}{$\begin{array}{l}\text { Sulfides } \\
\text { range } \\
(\mu \mathrm{m})\end{array}$} & \multirow[b]{2}{*}{$\begin{array}{l}\text { Opaques } \\
\text { (vol. \%) }\end{array}$} & \multicolumn{2}{|c|}{ Split of opaques } & \multirow[b]{2}{*}{$\begin{array}{l}\text { Low-temp. Tm. } \\
\text { oxidation no. }\end{array}$} & \multirow{2}{*}{\multicolumn{2}{|c|}{$\begin{array}{c}\text { EPMA } \\
\text { composition }\end{array}$}} \\
\hline & $\begin{array}{l}\text { Plag. lath } \\
\qquad(\mu \mathrm{m})\end{array}$ & Avg. & $\begin{array}{l}\text { Range } \\
\qquad(\mu \mathrm{m})\end{array}$ & Avg. & & & $\begin{array}{l}\text { Tm. } \\
(\%)\end{array}$ & $\begin{array}{c}\text { Sulfide } \\
(\%)\end{array}$ & & & \\
\hline 1 & 600 & 10 & $<1-10$ & 3 & $<1-6$ & 1.5 & 99 & 1 & $3-$ & - & - \\
\hline 2 & 600 & 40 & $<1-20$ & 3 & $<1-400$ & 1.4 & $>99.9$ & $<0.1$ & 3 & 0.68 & - \\
\hline 3 & 600 & 100 & $<1-30$ & 5 & $<1-1000$ & 1.8 & $>99.9$ & $<0.1$ & $2+$ & 0.51 & 0.8 \\
\hline 4 & 600 & 150 & $<1-15$ & 3 & $<1-15$ & 2.0 & 90 & 10 & $2+$ & 0.61 & 0.6 \\
\hline 5 & 1500 & 100 & $<1-50$ & 10 & $<1-200$ & 2.4 & 95 & 5 & $3+$ & 0.57 & 0.9 \\
\hline 6 & 800 & 50 & $<1-10$ & 1 & & 1.5 & 93 & 7 & $3-$ & - & - \\
\hline 7 & 600 & 75 & $<1-30$ & 5 & $<1-6$ & 2.2 & 95 & 5 & $2+$ & 0.64 & 0.5 \\
\hline 8 & 1000 & 100 & $<1-80$ & 15 & $<1-10$ & 2.3 & 98 & 2 & 3 & - & \\
\hline 9 & 1500 & 150 & $<1-100$ & 20 & $<1-150$ & 1.4 & 90 & 10 & $3+$ & 0.66 & 0.6 \\
\hline 10 & 1000 & 100 & $<1-60$ & 10 & $<1-400$ & 2.1 & 97 & 3 & $4+$ & - & - \\
\hline 11 & 600 & - & none & - & $<1-50$ & $<0.1$ & $>0$ & $<100$ & - & - & - \\
\hline 12 & 1500 & - & none & - & $<1-2000$ & 10 & $>0$ & $<100$ & - & - & - \\
\hline 13 & 160 & 40 & $80^{*}$ & $4^{*}$ & $<1-2000$ & 3 & $<0.1$ & $>99.9$ & 5 & 0.46 & 0.2 \\
\hline 14 & 600 & 40 & -* & - & $<1-1000$ & 5 & $<0.1$ & $>99.9$ & $5+$ & - & - \\
\hline 15 & 500 & - & -* & - & $<1-80$ & $<0.1$ & $<0.1$ & $>99.9$ & $5+$ & - & - \\
\hline 16 & 650 & 10 & $<1-30^{*}$ & 3 & $<1-1500$ & 5 & $<0.1$ & $<99.9$ & $5+$ & - & - \\
\hline 17 & 700 & 75 & $<1-100$ & 30 & $<1-200$ & 2.4 & $>99.9$ & $<0.1$ & $3+$ & 0.44 & 0.6 \\
\hline 18 & 800 & 150 & $<1-150$ & 50 & $<1-60$ & 1.5 & 95 & 5 & $3-$ & 0.62 & 0.7 \\
\hline 19 & 600 & 80 & $<1-400$ & 60 & $<1-20$ & 0.8 & 97 & 2 & 5 & 0.67 & 0.6 \\
\hline 20 & 1200 & 250 & $<1-250$ & 60 & $<1-40$ & 1.7 & 97 & 2 & 4 & 0.66 & 0.7 \\
\hline 21 & 1000 & 200 & $<1-150$ & 40 & $<1-150$ & 1.6 & 99 & 1 & $4+$ & 0.61 & 0.6 \\
\hline 22 & 1000 & 500 & $<1-100$ & 30 & $<1-100$ & 1.6 & 98 & 2 & $4-$ & 0.64 & 0.5 \\
\hline 23 & 1000 & 200 & $<1-200$ & 30 & $<1-100$ & 1.3 & 98 & 2 & 4 & 0.64 & 0.6 \\
\hline 24 & 1000 & 200 & $<1-100$ & 30 & $<1-100$ & 1.3 & 98 & 2 & 4 & 0.65 & 0.9 \\
\hline 25 & 1500 & 250 & $<1-100$ & 30 & $<1-100$ & 1.1 & 97 & 3 & $4+$ & 0.54 & 0.6 \\
\hline 26 & 1000 & 150 & $<1-150$ & 50 & $<1-60$ & 1.9 & 99 & 1 & $4++$ & 0.62 & 0.5 \\
\hline 27 & 1500 & 50 & $<1-150$ & 50 & $<1-40$ & 1.0 & 99 & 1 & $5-$ & 0.63 & 0.7 \\
\hline
\end{tabular}

Note: Tm. - titanomagnetite, ${ }^{*}$ - relict grains. Dash indicates quantities that were indeterminate or indeterminable.

crostructure within the grains tends to be indeterminate in samples of the upper section, but better defined in some samples of the lower section. In samples of the upper section the texture could only be described as granular, in some cases with uniform anisotropy throughout the grain, indicating one alignment of the anisotropic phase throughout, in other cases with a patchy degree of anisotropy and granulation. In Sample 9 a trellis pattern of granular wooly-edged, poorly defined lamellae was suggested throughout some grains under crossed polars. No bireflectance was seen in Samples 2-10.

All samples of the lower part of the section exhibit distinct anisotropy and bireflectance, both associated with a more coarse, granular, approaching clothlike, texture. Samples 19, 21, 26, and 27 contain the most wellformed lamellae, up to $0.5 \mu \mathrm{m}$ wide with clean-cut borders seen clearly both in crossed polars and plane polarized light. The lamellae separate areas of granular to cloth texture, containing smaller lamellae in the same orientation presumably along (111) planes of the host as the larger lamellae. The better-formed lamellae frequently persist into the nonopaque material about the edges of the grain. The nonopaque material, which resembles that formed by low-temperature alteration (probably sphene), stops abruptly where a large lamella lies across its path, thus protecting the granular intergrowth between the lamellae. In some cases the nonopaque material contains orientated elongate granules, rather surprisingly isotropic, which are presumed to be the remains of the corroded granular/cloth texture. Thus the lamellae appear to predate low-temperature alteration.

\section{ELECTRON OPTICAL ANALYSIS}

Selected titanomagnetite grains (grain size, 5-100 $\mu \mathrm{m}$ ) were probed using a Geoscan electron probe X-ray microanalyzer for $\mathrm{Fe}, \mathrm{Ti}, \mathrm{Mn}, \mathrm{Ca}, \mathrm{Zn}, \mathrm{Si}$, and $\mathrm{AI}$, and the analysis is expressed in the form of the general titanomagnetite/titanomaghemite formula stated previously. The cation $\mathrm{M}$ (excluding $\mathrm{Si}$ ) totaled about 0.1 per formula unit. The composition parameters $x$ and $z$ are listed in Table 2. Values of $z$ determined in this way are subject to a high uncertainty $(> \pm 0.2)$ and variations throughout the suite are probably not significant. The $x$ values $(\sim 0.6)$ are typical for titanomagnetite in basaltic crust. The spatial variations in composition within grains lie well below the resolving power of the probe beam, and the determined parameters represent the bulk composition of the intergrown phases. Attempts to detect and analyze the individual phases using a JEOL electron microscope with analysis facility was not successful, all analyses producing a titanomagnetite, TM60-like, result.

Analysis of the sulfide grains identified them as pyrite $\mathrm{FeS}_{2}$.

\section{DISCUSSION}

The magnetic data seem best interpreted as indicating the presence of fine-grain near-stoichiometric magnetite as the only magnetic phase. There is no direct evidence of magnetite or other magnetic species from the optical or electron microprobe investigations because the grain size of the magnetic species is at or below the limit of these techniques. The lack of such direct evidence by no means precludes the presence of magnetite as a constitu- 
ent of a fine scale and poorly developed intergrowth of phases.

The magnetic properties do not correlate with the titanomagnetite grain-size variations as the magnetic grain size results from the subdivision of the titanomagnetite grains. The volume fraction of magnetite inferred from the saturation magnetization data is less than and about one half of the titanomagnetite volume fraction, which is again consistent with some kind of intergrowth. The primary crystallized phase was titanomagnetite $(x$ $\sim 0.6$ ), as shown by the microprobe, and the question to be answered is by what path has the $x=0.6$ to $x=0$ transformation taken place.

Figure 1 shows the various mechanisms by which $\mathrm{Fe}_{3} \mathrm{O}_{4}$ may be produced. We can first discount mechanisms by which magnetite might come from without the diagram (precipitation, etc.). There is no optical evidence for discrete magnetite, although this does not preclude its existence intergrown with silicates. If the volume $\%$ of magnetite inferred from magnetic data had exceeded the volume $\%$ of titanomagnetite estimated optically, the presence of discrete magnetite would be highly probable. We can also disregard subsolvus exsolution as being a rare occurrence except in massive plutons where cooling is slow and the environment nonoxidizing. We are left with deuteric oxidation and/or maghemitization followed by inversion. For a given bulk composition ( $x$, $z)$, the coexisting phases are likely to be the same in either case, although the microstructural relations between the phases may well be different, at least on length scale, if the temperature/pressure conditions of inversion are different from those of deuteric oxidation. Laboratory inversion by heating of naturally maghemitized titanomagnetite (Inoue, 1982) produces a well-developed trellis pattern. Synthetic titanomaghemites are generally too fine grained to allow optical investigation after inversion. It is probable that magnetic measurements alone cannot distinguish whether an intergrowth of a given bulk composition resulted from deuteric oxidation or maghemitization followed by inversion.

Inversion appears in the literature only as a laboratory phenomenon although it must also be a natural occurrence. Reheating by the proximity of adjacent intrusives or extrusives could bring it about. A high geothermal gradient is also a possibility as is the pressure due to an overburden, temperature and pressure being expected to operate in tandem to bring about inversion. If $\mathrm{Ku}-$ shiro's (1960) results on pressure-induced inversion of maghemite are applicable to the titanomaghemites in nature, the occurrence of titanomaghemites at depths below the surface of the sea in excess of $1500 \mathrm{~m}$ seems inexplicable. The sea depth of $3500 \mathrm{~m}$ plus the $274.5 \mathrm{~m}$ of sediment overlying the basement in Hole 504B would seem to produce temperature and pressure greatly in excess of the values in the maghemite stability field. However, titanomaghemites were recovered intact from the Leg 69 section of Hole 504B. Because none were found in the present Leg 83 section, it may be that the stability field boundary conditions are exceeded somewhere between the two sections. The results of thermomagnetic analysis of Leg 70 samples, when available, will be of interest.

A possible and speculative history of the present material, based on known mechanisms, is as follows. The material of the upper section crystallized titanomagnetite (TM60), which cooled rapidly and was subsequently maghemitized to a significant degree. Subsequent burial under later extrusives and sediment raised the temperature and pressure so that the titanomaghemite inverted, producing magnetite as the principal magnetic phase. At the low temperatures $\left(<100^{\circ} \mathrm{C}\right)$ only a poorly developed microstructure results. The lower group also crystallized TM60, but slow cooling allowed deuteric oxidation to take place at temperatures of $>500^{\circ} \mathrm{C}$. Again magnetite is produced and the microstructure is better developed due to the higher temperatures.

Alternatively, a novel form of low-temperature magnetite-producing alteration may operate in these deepseated materials, possibly in combination with the previous two mechanisms. Conditions may be suitable for maghemitization, that is, warm circulating fluids actively leach iron out of the titanomagnetite or the spinel component of the inversion product. However, the pressure and temperature are too high for the survival of a cation-deficient spinel structure. The oxidation product would not then be titanomaghemite, or a magnetite/ maghemite solid solution member, but an intergrowth containing a progressively lower concentration of magnetite. The exceptional Samples 11, 12, 14, 15, and 16 perhaps represent a highly advanced state of such alteration. They come from a highly altered stockwork zone in which titanomagnetite is reported to have altered to sphene (Anderson et al., 1982).

More laboratory experiments on the stability field of titanomaghemites, or an attempted simulation of lowtemperature/high-pressure alteration process, may be helpful in determining which mechanisms may have operated in the deeper parts of the submarine crust and in assessing the consequences of such alteration on the contributions made to geomagnetic anomalies.

\section{CONCLUSIONS}

Although the primary magnetic mineral crystallizing in the basement rocks of the Leg 83 section of Hole 504B was titanomagnetite (TM60), the measured magnetic properties indicate the presence only of magnetite (TM0). The average magnetic properties of the studied material (with the exception of the weakly magnetic Samples $11,12,14,15$, and 16) can be ascribed to magnetite with grain size $<1 \mu \mathrm{m}$ present in concentration of about $0.5 \%$ and carrying a TRM acquired in a field of $\sim 30$ $\mathrm{A} / \mathrm{m}$.

A number of processes may have separately or together brought about the transformation of titanomagnetite to magnetite, but neither magnetic measurements nor optical or electron optical studies can or have been able to distinguish which path or paths the evolving mineral assemblage has taken. It is tempting to invoke the high-temperature/high-pressure conditions operating at depths on the order of $1000 \mathrm{~m}$ below seafloor as playing an important role in magnetite production. This may 
occur either through the inversion of titanomaghemite formed at an earlier time under lower pressures or by a hypothetical low-temperature/high-pressure process of oxidation by leaching of iron.

\section{ACKNOWLEDGMENTS}

We thank J. Honnorez, J. R. Cann, and A. C. Adamson for facilitating and encouraging this magneto-petrological investigation. D. F. is in receipt of a Natural Environment Research Council (NERC) research assistantship and J. H. of a NERC research studentship. The work also forms part of a NERC-sponsored research program "The petrological history of magnetic minerals in igneous rocks, studied by magnetic methods - the chemical basis of palaeomagnetism."

\section{REFERENCES}

Ade-Hall, J. M., Palmer, H. C., and Hubbard, T. P., 1971. The magnetic and opaque petrological response of basalts to regional hydrothermal alteration. Geophys. J. R. Astron. Soc., 24:137-174.

Anderson, R. N., Honnorez, J., Becker, K., Adamson, A. C., Alt, J. C., Emmerman, R., Kempton, P. D., Kinoshita, H., Laverne, C., Mottl, M. J., and Newark, R. L., 1982. DSDP Hole 504B, the first reference section over $1 \mathrm{~km}$ through Layer 2 of the oceanic crust. Nature, 300:589-594.

Day, R., Fuller, M., and Schmidt, V. A., 1977. Hysteresis properties of titanomagnetites: grain-size and compositional dependence. Phys. Earth Planet. Inter., 13:260-267.

Dunlop, D. J., 1981. The rock magnetism of fine particles. Phys. Earth Planet. Inter., 26:1-26.
Dunlop, D. J., and Prévot, M., 1982. Magnetic properties and opaque mineralogy of drilled submarine intrusive rocks. Geophys. J. $R$. Astron. Soc., 69:763-802.

Inoue, Y., 1982. Thermal process of titanomaghemite in volcanic rocks. J. Geomag. Geoelectr., 34:431-445.

Johnson, H. P., and Hall, J. M., 1978. A detailed rock magnetic and opaque mineralogy study of the basalts from the Nazca plate. Geophys. J. R. Astron. Soc., 52:45-64.

Johnson, H. P., and Merrill, R. T., 1973. Low temperature oxidation of a titanomagnetite and implications for palaeomagnetism. J. Geophys. Res., 78:4938-4949.

Kushiro, I., 1960. $\gamma-\alpha$ transition in $\mathrm{Fe}_{2} \mathrm{O}_{3}$ with pressure. J. Geomag. Geoelectr., 11:148-151.

O'Donovan, J. B., and O'Reilly, W., 1983. Magnetic properties of basalts from Hole 504B, Deep Sea Drilling Project Leg 69. In Cann, J. R., Langseth, M. G., Honnorez, J., Von Herzen, R. P., White, S. M. et al., Init. Repts. DSDP, 49: Washington (U.S. Govt. Printing Office), 721-726.

O'Reilly, W., 1983. The identification of titanomaghemites: model mechanisms for the maghemitization and inversion processes and their magnetic consequences. Phys. Earth Planet. Inter., 31:65-76.

Robins, B. W., 1972. Remanent magnetization in spinel iron oxides [Ph.D. dissert]. Universtiy of New South Wales, Sydney, N.S.W.

Ryall, P. J. C., and Ade-Hall, J. M., 1975. Radial variation of magnetic properties in submarine pillow basalts. Can. J. Earth Sci., 12: 1959-1969.

Tucker, P., and O'Reilly, W. 1980. The laboratory simulation of deuteric oxidation of titanomagnetites: effect on magnetic properties and stability of thermoremanence. Phys. Earth Planet. Inter., 23:112113.

Date of Initial Receipt: 21 April 1983

Date of Acceptance: 30 November 1983 